\title{
César Vallejo más allá de la vanguardia ${ }^{31}$ César Vallejo beyond the avant-garde
}

\author{
Julián Malatesta \\ Recibido: 25 de Agosto 2011. Aprobado: 15 de Septiembre 2011
}

\section{Resumen}

\section{Abstract \\ Palabras clave}

Keywords: César Vallejo; Peruvian poetry; Latin American poetry.

César Vallejo introdujo un debate memorable en el ambiente intelectual latinoamericano de la época, interrogaba el papel que juega el sentimiento en el hacer del arte y lo entendía como la condición ineludible para auscultar la riqueza de una cultura y el legado de la tradición. El control de la invención debe lograrse o ser regido por la corriente de la sensibilidad, por ese impulso vital que determina el modo de estar en un lugar y en un tiempo específico, esto es, en una época y en una sociedad en particular. Desconfiaba, Vallejo, del ejercicio puramente intelectual, que a la postre imponía a la obra de arte un aliento de artificialidad y que la hacía incapaz de conmover y de expresar con vigor la fuerza de su tiempo. Su polémica se orientaba a poner en tela de juicio los argumentos de Huidobro, quien colocaba todas sus esperanzas estéticas en la aplicación calculada de fórmulas, producto de un trabajo de laboratorio, de una disciplinada experimentación, es decir, del uso exclusivo de la razón.

Sería equivocado aventurar la idea según la cual Vallejo asociaría lo sensible con lo irracional y con ello se colocaría al lado de la vetusta superstición que imaginó a la poesía como una emanación de los arcanos y una manifestación espontánea de la condición

\footnotetext{
31 Ensayo de sistematización presentado en el Congreso internacional "César Vallejo, telúrico y magnético (18922012)" organizado por la Academia Peruana de la Lengua y la Facultad de Letras y Ciencias Humanas de la Universidad de San Marcos. 7, 8 y 9 de noviembre de 2012.
} 
humana; al contrario, entiende la sensibilidad como esa fuerza vital que reúne todos los grados de la razón en un hecho estético.

\begin{abstract}
¿Pero de qué razón se trata aquí? Menester es repetirlo. Se trata de una razón suprema, la razón del hombre y no de los hombres. El artista es el depositario de esta razón. Cuando él crea una obra maestra, no lo hace por haberse divorciado de los demás hombres, sino por haberlos enfocado y sintetizado universalmente, es decir, por haber expresado al hombre. La razón, en estética no es una mera diferencia de la razón del común de las gentes, sino la suma y ápice de ella. Entre la razón suprema del arte y la común de los hombres apenas existe diferencia aritmética de la suma respecto de las partes, más no una diferencia geométrica, que es la esencial en el arte. La razón en estética no es un grado superior de la razón humana, sino todos los grados reunidos.

Contra lo que pretenden los imaginistas, hay en estética una razón, ésa que acabamos de señalar, del mismo modo que existe una lógica estética, que es igualmente una lógica suprema y sintetizante de la común de los hombres. Lo difícil del artista es poseer el sentimiento de esta razón suprema y de esta lógica suprema de la creación. $^{32}$
\end{abstract}

No obstante, la discusión con Huidobro se mantuvo encerrada en una incomprensión mutua sobre sus afirmaciones teóricas y quizá en el desconocimiento por parte de Vallejo de Manifiesto de Manifiestos proclama elaborada por el poeta chileno en 1925 y que se publicó en 1935. En este documento Huidobro puntualiza una singular interpretación de la condición mimética del poema, para él, el acto creador es un acto de soberanía espiritual, y en este sentido, el creador imita el procedimiento con el cual la naturaleza le da origen a sus criaturas, busca situarse en el proceso del acto creador, no en su resultado, quiere gestionar desde el origen su obra y soberbiamente no admite ninguna intromisión, ni siquiera la de sus habituales recuerdos cotidianos. La materia prima con la que obra el poeta -su lenguaje, inscrito en una época y fundado en filiaciones individuales y colectivas-, ha de ser tratada con una templada racionalidad, moldeada en el rigor del cálculo y con la suficiente destreza para ejecutar mezclas, adherir fragmentos, hacer asociaciones y analogías todavía ausentes de las comunes representaciones. La única emoción que participa, la que el poeta admite, es aquella que brota festiva y escandalosa del hallazgo que acontece en los pequeños procedimientos de laboratorio, donde de tanto

\footnotetext{
${ }^{32}$ Vallejo, César. El retorno a la razón, en variedades, núm. 1.019, Lima, 10 de septiembre de 1.927, citado por Enrique Ballón Aguirre en el prólogo: Para una definición de la escritura de Vallejo, Obra poética completa, Biblioteca Ayacucho, Caracas, 1985. Pp. XXXI - XXXII.
}

Poligramas 36, segundo semestre 2011, ISSN 0120-4130. 
en tanto hace su aparición el descubrimiento, pero donde también se asoma la desolación y la pesadumbre. El poema final, como el árbol, es quién asiste a la celebración.

El poeta es un motor de alta frecuencia espiritual, es quien da vida a lo que no la tiene; cada palabra, cada frase adquiere en su garganta una vida propia y nueva, y va a anidarse palpitante de calor en el alma del lector.

Ser poeta consiste en tener una dosis tal de particular humanidad, que pueda conferírsele a todo lo que pase a través del organismo cierta electricidad atómica profunda, cierto calor nunca dado por otros a esas mismas palabras, cierto calor que hace cambiar de dimensión y color a las palabras. ${ }^{33}$

Este acuerdo tácito sobre el sentimiento y la razón como expresión de la más alta espiritualidad del género humano, disuelve el equívoco sostenido por los dos poetas y advierte de una extraordinaria visión del hecho poético como producto de la conciencia, resultado del más esmerado oficio y quizá de la condición vulnerable del poeta para captar con el ejercicio pleno de los sentidos la dimensión profunda que el lenguaje en asociaciones ilícitas, esto es, en contravía de los modos en que suele manifestarse la lógica del habla cotidiana, revela como un acontecimiento único. Ni para Vallejo, ni para Huidobro, el poema es un asunto de la espontaneidad, tampoco de una simétrica conversación con el modelo exterior, ni de un diálogo con el arcano de los sueños. La obra de Arte como acontecimiento estético y por ello como expresión de la cultura, es autónoma, no tiene iguales ni antecedentes en el mundo real, salvo aquellos rasgos que ella evoca de modo fragmentario, que ella escruta, somete a crítica y renueva tanto de fuentes literarias como de los imaginarios sociales. Es su capacidad de diálogo con el pasado y con su presente lo que la constituye como una necesidad para la evolución espiritual del género humano.

Esta suerte de alegoría constitutiva del poema sólo establecería una conexión sumisa con su anterioridad (esto es, con el ámbito de la vida), si el poema mismo no comportara una dimensión irónica que le permitiera disolver la identidad y con ello fundar la crítica y suscitar cambios profundos en el pensamiento. Se trata de la vieja afirmación de Heidegger, según la cual, el poema es símbolo, alegoría e ironía, es decir, es histórico, es

\footnotetext{
${ }^{33}$ Huidobro Vicente. Obra selecta, Manifiesto de Manifiestos, Biblioteca Ayacucho, Caracas, 1989. Pp. 326-327.
} 
un diálogo y es una renovación. En este sentido el símbolo es en el poema el soporte material o el hecho de lengua que espera ser moldeado y dotado de nuevos contenidos y significados por la intervención alegórica, por esa fuerza exploradora de su origen y de su contexto histórico, pero es la ironía el dispositivo por el cual la obra se constituye como única, pues éste opera en la disolución de la identidad, en el destrozo de la mimesis y con ello asegura que la obra se constituya en mundo posible.

Las vanguardias anhelaron derrotar la dimensión alegórica por cuanto ésta amarraba la obra a un pasado y con ello restringía su condición de novedad, creían posible instaurar una ruptura absoluta con la tradición y con el entorno social y cultural y quizá por ello terminaron en sus aventuras experimentales produciendo sonidos guturales con la vana ilusión de hallarse fundando un lenguaje nuevo, de tal modo que en este empeño también hicieron desparecer de la obra su condición irónica y con ello liquidaron el pensar, el nacimiento de una crítica y la instauración de un renovado diálogo con nuestra cultura. He aquí la impetuosa herencia del poeta César Vallejo, ejecutó una obra donde las tradiciones literarias, las representaciones religiosas y el lenguaje popular se dieron cita y fueron tratadas con el cincel de la ironía, con esa devastadora operación del intelecto para poner al lector al frente de su propio juicio crítico.

¡Y si después de tantas palabras, no sobrevive la palabra!

¡Si después de las alas de los pájaros, no sobrevive el pájaro parado!

¡Más valdría en verdad, que se lo coman todo y acabemos!

¡Haber nacido para vivir de nuestra muerte!

¡Levantarse del cielo hacia la tierra

por sus pequeños desastres

y espiar el momento de apagar con su sombra su tiniebla!

¡Más valdría, francamente,

que se lo coman todo y que más da...!

¡Y si después de tanta historia, sucumbimos, no ya de eternidad, sino de cosas sencillas, como estar en la casa o ponerse a cavilar!

$¡ Y$ si luego encontramos, de buenas a primeras que vivimos, a juzgar por la altura de los astros, por el peine y las manchas del pañuelo! ¡Más valdría en verdad, 
que se lo coman todo, desde luego!

Se dirá que tenemos

en uno de los ojos mucha pena

y también en el otro, mucha pena...

entonces... ¡Claro...! Entonces...!ni palabra! ${ }^{34}$

En defensa de esa sensibilidad concebida como potencia de la razón suprema, se opone Vallejo a la creencia, muy difundida entonces, según la cual lo nuevo haría expresión en el arte y sobre todo en la poesía, por el uso masivo de vocablos y de artefactos propios de la reciente vida moderna. Por esta vía, también deviene la poesía en artificio y el poder de la imagen poética se debilita en sus propias restricciones alegóricas.

Poesía nueva ha dado en llamarse a los versos cuyo léxico está formado de las palabras "cinema, motor, caballos de fuerza, avión, radio, jazz-band, telegrafía sin hilos", y en general, de todas las voces de las ciencias e industrias contemporáneas, no importa que el léxico corresponda o no a una sensibilidad auténticamente nueva. Lo importante son las palabras.

Pero no hay que olvidar que esto no es poesía nueva ni antigua, ni nada, los materiales artísticos que ofrece la vida moderna, han de ser asimilados por el espíritu y convertidos en sensibilidad. El telégrafo sin hilos, por ejemplo, está destinado, más que a hacernos decir "telégrafo sin hilos", a despertar nuevos temples nerviosos, profundas perspicacias sentimentales, amplificando vivencias y comprensiones y densificando el amor; la inquietud entonces crece y se exaspera y el soplo de la vida, se aviva. Esta es la cultura verdadera que da el progreso; este es su único sentido estético, y no el llenarnos la boca con palabras flamantes. Muchas veces las voces nuevas pueden faltar. Muchas veces un poema no dice "cinema", poseyendo, no obstante, la emoción cinética, de manera obscura y tácita, pero efectiva y humana. Tal es la verdadera poesía nueva.

Tal vez en un sentido diferente al de Borges, la contradicción de César Vallejo con la vanguardia toma un matiz político, pues el espíritu revolucionario que ésta debe encarnar, no puede distraerse en la pantomima de los efectos; en los ruidos y escándalos de la innovación; en los juegos pirotécnicos del lenguaje ni en sus explosivas transgresiones al mismo. Ser revolucionario en arte es educar la sensibilidad para escrutar a fondo las pasiones humanas; indagar por las condiciones históricas en que éstas acaecen; explorar

${ }^{34}$ Vallejo, César. Obra Poética. Colección Archivos, Unesco, Madrid. 1988. p. 352. 
lo que hay de porvenir en el pasado y reconocer críticamente lo que hay de pasado en nuestra pequeña constelación del presente.

No se trata de una tarea mesiánica, ni se concibe al poema como la puerta que se abre a un futuro diseñado de antemano, previamente templado en los hornos de la razón; se trata de entender la obra de arte como ese instrumento que tiene la propiedad de hacer pública la miseria del género humano al mismo tiempo que delata su enorme riqueza espiritual; que descubre de modo implacable las taras que entorpecen su devenir y manifiesta lo que hay de creador en su ocupación del mundo, y esto, a su juicio, no es conseguible simplemente con el trabajo de joyería mecánica, con el herramientario de la técnica; la obra de arte exige un operario de la vida común; comprometido sensiblemente con su historia y su época; afecto a todos los oficios; vulnerable a todos los saberes; en otras palabras, como diría Benjamin, capaz de interrogar el sensorium de su tiempo.

\section{Un hombre pasa con un pan al hombro...}

Un hombre pasa con un pan al hombro ¿Voy a escribir después sobre mi doble?

Otro se sienta, ráscase, extrae un piojo de su axila, mátalo ¿Con qué valor hablar del psicoanálisis?

Otro ha entrado a mi pecho con un palo en la mano ¿Hablar luego de Sócrates al médico?

Un cojo pasa dando el brazo a un niño ¿Voy, después, a leer a André Bretón?

Otro tiembla de frío, tose, escupe sangre ¿Cabrá aludir jamás al Yo profundo?

Otro busca en el fango huesos, cáscaras ¿Cómo escribir, después, del infinito?

Un albañil cae del techo, muere y ya no almuerza. ¿Innovar luego el tropo, la metáfora?

Un comerciante roba un gramo en el peso a un cliente ¿Hablar, después, de cuarta dimensión?

Un banquero falsea su balance ¿Con qué cara llorar en el teatro? 
Un paria duerme con el pie a la espalda

¿Hablar, después, a nadie, de Picasso?

Alguien va en un entierro sollozando

¿Cómo luego ingresar a la academia?

Alguien limpia un fusil en la cocina

¿Con qué valor hablar del más allá?

Alguien pasa contando con sus dedos

¿Cómo hablar del no-yo sin dar un grito? ${ }^{35}$

Se ha dicho que la modernidad es obsolescencia, velocidad, degradación, tiempo intensivo, disolución de la estabilidad, abolición de lo permanente, fugacidad, y que este desajuste de la temporalidad dio origen a una nueva sensibilidad y con ello a una nueva manifestación de las formas artísticas, a la aparición en plástica de los originales múltiples propiciados por las técnicas de reproducción, o a obras que disolvían, al decir de Benjamin, el aura y que incorporaban la ruina como parte de su naturaleza. Tal vez esta sea la justificación histórica del proyecto de las Vanguardias, pero habría que preguntarse si en ese legado de fallidas resoluciones y de importantes aciertos, hay un elemento que permita unificar tan disímiles propósitos en distantes y adversos movimientos. Aún con su obstinada negación a inscribirse en una de esas altaneras manifestaciones acaecidas en las primeras décadas del siglo XX y con su definida propensión a pensar desde su propio continente y con la lengua moza de estos pueblos, el devenir de la obra de Arte, creo que en Vallejo se hace público el aporte que las diversas corrientes del espíritu vanguardista, en sus mejores momentos, pusieron en común a través de sus obras: Hacer concurrir como imagen la dimensión alegórica y la ironía. Esa vieja máxima que se volvió proverbio, formulada por Reverdy, en 1918 según la cual:

La imagen es una creación pura del espíritu, la imagen no puede nacer de una comparación, sino del acercamiento de dos realidades más o menos lejanas. Cuanto más lejanas o justas sean las concomitantes de las dos realidades objeto de aproximación, más fuerte será la imagen, más fuerza emotiva y más realidad poética tendrá. ${ }^{36}$

\footnotetext{
${ }^{35}$ Vallejo, Cesar. Obra Poética Completa, Poemas Humanos, Biblioteca Ayacucho, Caracas, 1985. p. 184.

${ }^{36}$ Revérdy, Pierre. Nord Sud, marzo de 1918. En: Cirlot, Lourdes. Primeras Vanguardias Artísticas, Labor, Barcelona, España, 1993. p. 142.
} 
Huidobro su compañero de andanzas poéticas y editoriales escribió en el Manifiesto de manifiestos que he citado:

(...) El poeta es aquel que sorprende la relación oculta que existe entre las cosas más lejanas, los ocultos hilos que las unen. Hay que pulsar aquellos hilos como las cuerdas de un arpa, y producir una resonancia que ponga en movimiento las dos realidades. La imagen es el broche que las une, el broche de luz... ${ }^{37}$

Otro tanto hace el joven Borges quien decidió unir la frase de su maestro Ortega y Gasset, quien afirmó que: "La poesía es hoy el álgebra superior de las metáforas"38 con la propuesta de Revérdy y de Huidobro: “...abominamos los matices borrosos del rubenismo y nos enardeció la metáfora por la precisión que hay en ella, por su algebraica forma de correlacionar lejanías." 39

Para César Vallejo este encuentro de la alegoría y de la ironía en la constitución de la imagen es un duelo y es un desalojo, hay cierta reminiscencia romántica en su abordaje, pero el poeta presenta un yo despreocupado de su trascendencia, igualado a los sujetos de su tierra y de su tiempo, con la conciencia del carácter inacabado de la obra y con el desasosiego de no encontrar la respuesta a esos interrogantes que suele instalar como espinas en el espinazo del mundo. En el poeta romántico el carácter inconcluso de la obra ya era el gesto irónico y con ello la manifestación de su atribulada existencia, en el poeta de vanguardia, la conciencia del carácter efímero del poema y su constitución como imagen era motivo de orgullo y constatación del carácter transitorio del arte. En el uno era el sufrimiento y en el otro era el humor. Pero César Vallejo se instala en el vértice de estos dos estados del alma. Cuando su exploración se ahoga en esos ámbitos oscuros de la historia y del origen, el poeta sufre la ausencia de una explicación cabal y profunda a sus interrogantes, más cuando decide dirigir su catalejo hacia la faena espiritual y material de los hombres, el poeta ríe de esa diaria inconsistencia que es el hecho de vivir. Se trata de un diálogo que se iguala con sus semejantes y con ellos, quiero decir el lector, edifica la diferencia. Ironía y alegoría ejercen su concubinato armando casa en la imagen y

\footnotetext{
${ }^{37}$ Huidobro Vicente. Op. Cit. p. 322.

${ }^{38}$ Ortega y Gasset, José. La Deshumanización del Arte, Ideas sobre la Novela, Revista de Occidente, Espasa Calpe, Madrid, 1.928. p. 46.

${ }^{39}$ Borges, Jorge Luis. “Acotaciones”, Publicado en la revista Proa, No 1. Agosto de 1924, en Schwartz, Jorge. Las Vanguardias Latinoamericanas, textos programáticos y críticos, Cátedra, Madrid, 1.991. p. 110.
} 
acercando sus temporalidades no con la coincidencia y la identificación, sino con la diferencia y la disociación. Así se produce el humor y se ejecuta el duelo, ambos tienen un carácter momentáneo y fugaz, el lector quien es el encargado de culminar el acontecimiento, actúa como el hombre moderno en las grandes urbes, vulnerable al shock y al sobresalto.

Permítanme culminar con este poema:

\section{Un momento más grave de la vida}

Un hombre dijo:

-El momento más grave de mi vida estuvo en la batalla del Marne, cuando fui herido en el pecho.

Otro hombre dijo:

-El momento más grave de mi vida, ocurrió en un maremoto de Yocohama, del cual salvé milagrosamente refugiado bajo el alero de una tienda de lacas.

Y otro hombre dijo:

-El momento más grave de mi vida acontece cuando duermo de día.

Y otro dijo:

-El momento más grave de mi vida ha estado en mi mayor soledad.

Y otro dijo:

-El momento más grave de mi vida fue mi prisión en una cárcel del Perú.

Y otro dijo:

-El momento más grave de mi vida es el haber sorprendido de perfil a mi padre.

Y el último hombre dijo:

-El momento más grave de mi vida no ha llegado todavía.

(Vallejo, César. Op. Cit. P. 311) 


\section{Bibliografía}

Benjamin, Walter. El concepto de crítica de arte en el romanticismo alemán, Península 211, Barcelona, España, 1988.

Poesía y capitalismo, Iluminaciones II, Taurus, Madrid, 1999.

Discursos interrumpidos I, Taurus, Madrid, 1982.

Benko, Susana. Vicente Huidobro y el cubismo, Monte Ávila Editores, Caracas, 1993.

Bravo, Víctor. Los poderes de la ficción. Monte Ávila Editores, Caracas, 1993. . Figuraciones del poder y la ironía. Monte Ávila Editores, Universidad de los Andes, Caracas, 1996

Cirlot, Lourdes. Primeras Vanguardias Artísticas, Labor, Barcelona, España, 1993.

De Man, Paul. Visión y ceguera: Ensayos sobre la retórica de la crítica contemporánea, Universidad de Puerto Rico, Puerto Rico, 1991.

Heidegger, Martin. Arte y poesía. Fondo de Cultura Económica, México, D. F., 1995.

Huidobro Vicente. Obra selecta, Biblioteca Ayacucho, Caracas, 1989.

Malatesta, Julián. La imagen poética, la asonada americana. Universidad de los Andes, Mérida, Venezuela, 2008.

Ortega Y Gasset, José. La Deshumanización del Arte, Ideas sobre la Novela, Revista de Occidente, Espasa Calpe, Madrid, 1.928.

Schwartz, Jorge. Las Vanguardias Latinoamericanas, textos programáticos y críticos, Cátedra, Madrid, 1.991.

Vallejo, César. Obra Poética. Colección Archivos, Unesco, Madrid. 1988. . Obra Poética Completa, Biblioteca Ayacucho, Caracas, 1985. 